New initiatives allow access to scientific research and colleagues through membership and media.

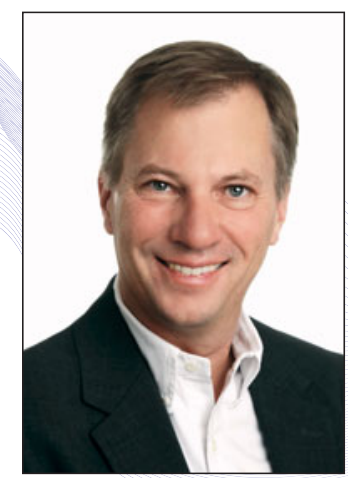

\section{Engaging materials scientists and students around the world}

Oliver Kraft

2015 MRS President

Interdisciplinary. Broadly inclusive. Egalitarian. These are meaningful and powerful words. And for us, as members of the Materials Research Society (MRS), they are at the very core of our Mission, Vision, and Values. We constantly strive to provide programs, products, and services that are important to our global and diverse membership. But we need to ask ourselves, "Are these really accessible to everyone in the worldwide materials community?"

To that end, and as part of MRS's 40th Anniversary, we introduced free electronic memberships for students in developing countries - countries defined as lower-income or lower-middle-income economies by the World Bank. Funded by the Materials Research Society Foundation, these memberships enable students to connect with colleagues from around the world, form MRS University Chapters to support on-campus activities, and enjoy free electronic access to all MRS publications. We also actively seek to engage our students in the MRS OnDemand ${ }^{\circledR}$ Webinar Series, which builds upon monthly themes presented in MRS Bulletin.

Now, MRS is taking this effort one step further. The Board of Directors recently approved a discounted-rate option for professional members working in developing countries. These memberships will begin with our January 2016 membership cycle, with details on eligibility and rate structure available shortly at www.mrs.org/dev-countries-member. Also in 2016, MRS will launch a new travel-grant program for invited speakers from developing countries.

This new membership option and travel-grant program are exciting and significant, and are additional ways we are striving toward MRS's Vision to build a dynamic, interactive, global community of materials researchers. We hope that this will allow us to more fully engage materials scientists in countries that can both contribute to, and benefit from, the Society's programs. As is the case for all MRS members, these new members will have:

- access to, and inclusion in, the MRS Member Directory - an online database that allows members to add photos, a brief bio, and links to social media sites, and is widely considered an excellent networking tool.

- online access to MRS Bulletin, consistently ranked in the top $10 \%$ of materials science journals.

- an electronic subscription to the Journal of Materials Research (JMR) - providing access to full-text articles from the Journal's inception in January 1986 to the current issue. 
- online access to the letters and prospectives journal, MRS Communications.

- access to the newly published MRS Energy \& Sustainability-A Review Journal, focused on key topics in materials research and development as they relate to energy and sustainability.

- access to MRS Advances, a new peer-reviewed online-only journal featuring impactful research presented at MRS Meetings (beginning with manuscripts from the $2015 \mathrm{MRS}$ Fall Meeting).

- access to over 100,000 full-text papers archived in the MRS Online Proceedings Library Archive-Volume 1 through the 2015 MRS Spring Meeting.

- discounted rates for MRS Meetings and Workshops.

- opportunities to expand their careers or company via the new MRS Career Central.

- volunteer opportunities in MRS committees and task forces.

- grassroots project funding opportunities via the Materials Research Society Foundation.

To be clear, the goal of this program is not to increase our membership numbers, but rather to enable those materials scientists and engineers, for whom the cost of membership is outside their means, to access scientific research and colleagues around the world. And that furthers the MRS Mission and Vision - to provide a framework in which the worldwide materials community can convene, collaborate, integrate, and advocate.

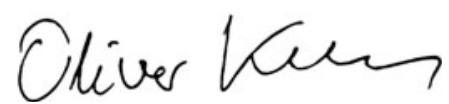

Oliver Kraft

2015 MRS President

\section{$M|R| S$}

COREVALUES

- Promoting TECHNICAL EXCELLENCE

- Being VISIONARY and DYNAMIC

- Being

INTERDISCIPLINARY

- Being BROADLY

INCLUSIVE and EGALITARIAN

WANT TO HELP?

Please consider joining the MRS Member Engagement Committee. For more information, or suggestions, contact info@mrs.org. 


\section{Surrounding You with Expertise \& Support}

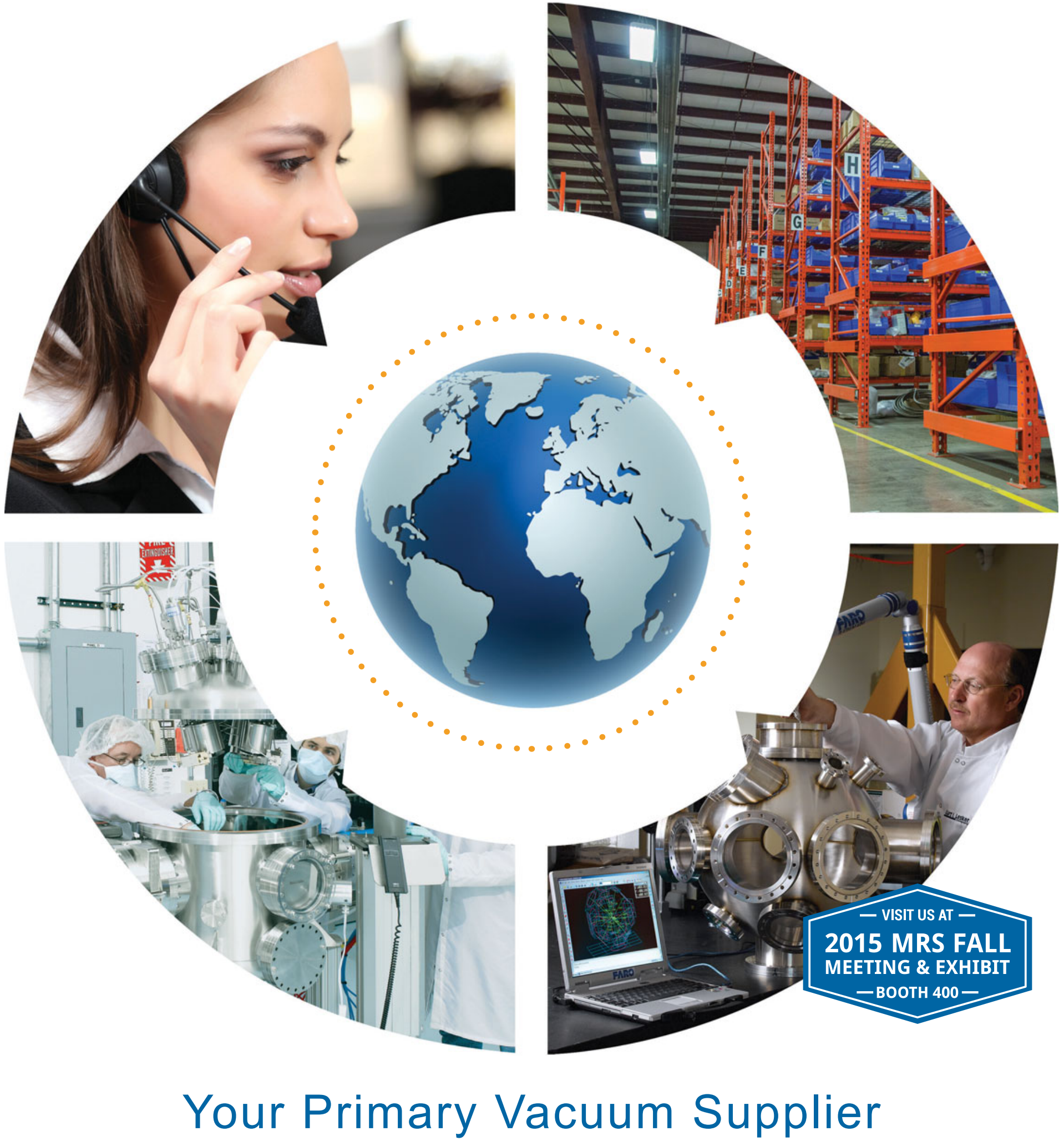

Highly Professional

Customer Service
Largest Inventory of Vacuum Components
Renowned Technical

Expertise
Highest Quality

Products Available 